\title{
Retrospective Analysis of the Results of Adjuvant Chemotherapy in Breast Cancer Patients with 10 or More Positive Nodes: Non- randomized Comparison of Adriamycin-Containing Regimens
}

\author{
Jin-Hee Ahn, M.D. ${ }^{1}$, Haeseoung Bahng, M.D. ${ }^{1}$, Jeong-Gyun Kim, M.D. ${ }^{1}$, Sung-Bae Kim, M.D. ${ }^{1}$, Sei-Hyun \\ Ahn, M.D. ${ }^{2}$, Hyesook Chang, M.D. ${ }^{3}$, Jung-Shin Lee, M.D. ${ }^{1}$, Sang-Hee Kim, M.D. ${ }^{1}$ and Woo Kun Kim, M.D. ${ }^{1}$ \\ Departments of ${ }^{1}$ Medicine, ${ }^{2}$ Surgery and ${ }^{3}$ Radiation-Oncology, Asan Medical Center, University of Ulsan College of Medicine, \\ Seoul, Korea
}

Purpose: To evaluate the results of adriamycin-based adjuvant chemotherapy with or without high dose chemotherapy (HDC) with stem cell transplantation (SCT) in breast cancer with 10 or more positive axillary nodes.

Materials and Methods: Seventy-one breast cancer patients who had undergone surgery and had 10 or more positive axillary nodes were included in this study held between January 1997 and December 1999. The pathologic and clinical records were reviewed retrospectively.

Results: Twenty-nine patients were treated with adriamycin followed by 8 courses of CMF (group I); 22 patients received 4 courses of adriamycin and 7 patients received 3 courses of adriamycin. Twenty-six patients received median 6 courses of CAF (group II) and 16 patients underwent HDC and autologous SCT (group III). With a median follow-up of 27.1 months, relapses were observed in 24 patients $(33.8 \%)$ and the 3-year disease-free survival

\section{INTRODUCTION}

Although adjuvant chemotherapy has been proven to be beneficial in breast cancer patients, patients with 10 or more involved axillary nodes have a very poor prognosis $(1,2)$. In such patients, the 5-year disease free survival (DFS) ranged from $20 \%$ to $30 \%$ in spite of adjuvant chemotherapy such as CMF or a similar regimen $(3,4)$. Adriamycin is known for its efficacy in breast cancer treatment and has been investigated as a means improving results in both metastatic diseases and in an adjuvant setting $(5 \sim 8)$. Buzdar et al. (7) treated 283

Correspondence: Woo Kun Kim, Department of Hematology/Oncology, Asan Medical Center, University of Ulsan College of Medicine, 388-1, Pungnap-dong, Songpa-gu, Seoul 138-736, Korea. (Tel) 02-3010-3210, (Fax) 02-3010-6961, (E-mail) wkkim@amc.seoul.kr

Received October 15, 2001, Accepted April 2, 2002

Preliminary results of this study were presented at Annual Congress of Korean Cancer Association 27, 2001
(DFS) rate was $57.1 \%$; group I/II $55.4 \%$, and group III $62.7 \%$. The three-year overall survival (OS) rate was $86.1 \%$; group I/II $83.0 \%$, group III $93.8 \%$. There were no difference in the 3 -year DFSs or in the OSs of group I and group II. However, patients who received only 3 courses of the sequential adriamycin in group I showed a significantly poorer 3-year OS than those that received 4 courses of adriamycin $(42.9 \%$ vs. $95.5 \%)$.

Conclusion: Our study shows that adriamycin-containing combination chemotherapy is as effective as HDC with SCT in patients with 10 or more positive axillary lymph nodes judging by 3-year DFS and OS, and shows that three courses of adriamycin seems to be inadequate. (Cancer Research and Treatment 2002;34:84-90)

Key Words: Breast neoplasm, Adjuvant chemotherapy, Adriamycin, Stem cell transplantation

patients with 10 or more positive nodes using adriamycincontaining adjuvant chemotherapy and obtained a 5-year DFS of $41 \%$.

Bonadonna et al. (9) reported that when adriamycin was used before CMF in the sequential regimen, 5-year DFS was $50 \%$ and 10-year DFS was 29\%. The poor prognosis of these patients encouraged many investigators to study more aggressive treatments using HDC with hematopoietic support. However, in spite of earlier encouraging reports, no convincing evidence exists concerning the superiority of HDC over conventional dose chemotherapy $(10 \sim 12)$.

Since 1997, we have treated these patients with adriamycinbased chemotherapy with or without HDC and SCT. We discussed the option of chemotherapy versus HDC and SCT in patients with 10 or more positive nodes. Patients who elected not to receive HDC with autologous SCT were treated with an adriamycin-based chemotherapy, mainly CAF or sequential adriamycin followed by CMF. This study was undertaken to review the results of these three different treatment regimens in these patients. 


\section{PATIENTS AND METHODS}

Between January 1997 and December 1999, 91 patients underwent modified radical mastectomy (MRM) or breastconserving surgery (BCO) plus full axillary node dissection and had 10 or more positive nodes. Among these 91 patients, 2 were male, supraclavicular lymph node (SCLN) or bone metastasis was detected immediately postoperatively in 4 patients, one was treated with adjuvant CMF, 2 were treated with only 3 courses of adriamycin due to follow up loss and a traffic accident, and 11 did not receive adjuvant chemotherapy (patient's refusal in 5 , transfer to other hospital in 6). These were excluded from this study. Therefore, a total of 71 female patients who were treated with either adriamycin-based combination chemotherapy or HDC and SCT were included in this study. We reviewed the pathologic data and analyzed the clinical outcome by retrospectively reviewing medical records.

The postoperative adjuvant chemotherapy regimens used are summarized in Table 1. The decision upon HDC with SCT or conventional dose chemotherapy was made by patients after a full discussion of the treatment options. The chemotherapy regimen used in patients who opted not to go through HDC was chosen by the attending oncologists. Four courses of adriamycin followed by 8 courses of CMF (A-CMF, group I) were planned in 29 patients. However, 7 patients missed the $4^{\text {th }}$ adriamycin course because of a calculation error. CAF followed by HDC with autologous SCT was intended in 20 patients, but 4 patients refused the HDC after 4 courses of CAF and chose to receive 2 or more courses of CAF. As a result, 26 patients received CAF chemotherapy (group II) and 16 patients received 4 courses of CAF followed by $\mathrm{HD} \mathrm{CTCb}$ (high dose cyclophosphamide, thiotepa, and carboplatin) with autologous SCT (group III). Before the start of adjuvant chemotherapy, abdominal ultrasound and bone scan were performed to evaluate metastasis in all patients. No bone marrow studies were performed in any group of patients.

DFS was calculated as the time elapsed from the date of surgery to the first documented evidence of disease recurrence, and OS was determined from the date of surgery to the date of death. Univariate analysis of the prognostic factors affecting the survival rate was performed with various histopathologic characteristics and adjuvant therapy regimens. Each categorical variable was compared by using the chi-square test. The Kaplan-Meier method was used to estimate survival and statistical differences were assessed by using the log-rank test, and $P$-values were based on a two-sided significance test.

\section{RESULTS}

\section{1) Patients characteristics and adjuvant therapy}

The median age of all 71 patients was 46 years (range 30 $67)$ and $47(66.2 \%)$ patients were premenopausal. Thirty (42.2\%) patients had more than 20 lymph nodes. The patient and histopathologic characteristics of the 3 treatment groups are listed in Table 2. With the exception of radiotherapy, patient characteristics were evenly distributed over the 3 groups. Forty-seven patients received adjuvant radiotherapy of 6,000 cGy to the ipsilateral chest wall and the supraclavicular fossa; $37(77.1 \%)$ in group I/II, and $6(37.5 \%)$ in group III ( $P$-value 0.006). Radiotherapy was administered concomitantly with adjuvant chemotherapy (CMF phase) after the $4^{\text {th }}$ course of adriamycin in group I, but was administered subsequently after chemotherapy in group II. Adjuvant chemotherapy was started within a median 26 days of surgery (range 13 $\sim 68$ days). The median total dose of adriamycin received was $300 \mathrm{mg} / \mathrm{m}^{2}$ (range $225 \sim 300 \mathrm{mg} / \mathrm{m}^{2}, 29 \mathrm{mg} / \mathrm{m}^{2} /$ week) in group I, and 360 $\mathrm{mg} / \mathrm{m}^{2}$ (range $160 \sim 480 \mathrm{mg} / \mathrm{m}^{2}, 21 \mathrm{mg} / \mathrm{m}^{2} /$ week) in group II. All patients with ER-positive tumors were treated with tamoxi-

Table 1. Adjuvant chemotherapy regimens

\begin{tabular}{|c|c|c|}
\hline & Regimen & Doses \& schedule \\
\hline \multirow[t]{2}{*}{ Group I } & 4A-CMF $(n=22)$ & $\begin{array}{l}\text { Adriamycin }\left(75 \mathrm{mg} / \mathrm{m}^{2} \mathrm{IV}, \mathrm{D} 1 \text {, every } 3 \text { weeks }\right) \times 4 \text { cycles } \\
\text { Followed by } \\
\text { Cyclophosphamide }\left(600 \mathrm{mg} / \mathrm{m}^{2}, \mathrm{IV}, \mathrm{D} 1\right) \\
\left.\begin{array}{l}\text { Methotrexate }\left(40 \mathrm{mg} / \mathrm{m}^{2}, \mathrm{IV}, \mathrm{D} 1\right) \\
\text { 5-Fluorouracil }\left(600 \mathrm{mg} / \mathrm{m}^{2}, \mathrm{IV}, \mathrm{D} 1\right)\end{array}\right] \begin{array}{l}\text { every } 3 \text { weeks } \\
\times 8 \text { cycles }\end{array}\end{array}$ \\
\hline & 3A-CMF $(n=7)$ & $\begin{array}{l}\text { Adriamycin }\left(75 \mathrm{mg} / \mathrm{m}^{2} \mathrm{IV}, \mathrm{D} 1 \text {, every } 3 \text { weeks }\right) \times 3 \text { cycles } \\
\mathrm{CMF} \times 8 \text { cycles }\end{array}$ \\
\hline Group II & CAF $(n=26)$ & $\left.\begin{array}{l}\text { Cyclophosphamide }\left(600 \mathrm{mg} / \mathrm{m}^{2}, \mathrm{IV}, \mathrm{D} 1\right) \\
\text { Adraimycin }\left(60 \mathrm{mg} / \mathrm{m}^{2}, \mathrm{IV}, \mathrm{D} 1\right) \\
\text { 5-Flurouracil }\left(600 \mathrm{mg} / \mathrm{m}^{2}, \mathrm{IV}, \mathrm{D} 1\right)\end{array}\right] \begin{array}{l}\text { every } 3 \text { or } 4 \\
\text { weeks } \\
\geq 4 \text { cycles }\end{array}$ \\
\hline Group III & HDC $(n=16)$ & $\begin{array}{l}\text { CAF } \times 4 \text { cycles Followed by } \\
\text { High-dose chemotherapy (CTCb) \& autologous SCT } \\
\text { Cyclophosphamide }\left(1,500 \mathrm{mg} / \mathrm{m}^{2}, \mathrm{IV} \text {, D-7 to D- } 4\right) \\
\text { Mesna }\left(1,500 \mathrm{mg} / \mathrm{m}^{2}, \mathrm{IV}, \mathrm{D}-7 \text { to D-3) }\right. \\
\text { Thiotepa }\left(125 \mathrm{mg} / \mathrm{m}^{2}, \mathrm{IV}, \mathrm{D}-7 \text { to D- } 4\right) \\
\text { Carboplatin }\left(200 \mathrm{mg} / \mathrm{m}^{2}, \mathrm{IV}, \mathrm{D}-7 \text { to D-4) }\right.\end{array}$ \\
\hline
\end{tabular}


Table 2. Patient characteristics according to treatment groups

\begin{tabular}{|c|c|c|c|c|}
\hline & \multicolumn{3}{|c|}{$\mathrm{HDC}^{*}(-)$} & \multirow{2}{*}{$\frac{\text { HDC }(+)}{\text { Group III }(\mathrm{n}=16)}$} \\
\hline & Group I+II $(\mathrm{n}=55)$ & Group I $(n=29)$ & Group II $(n=26)$ & \\
\hline Age, years (med.) & 48 & 51 & 46 & 40 \\
\hline Range & $30 \sim 67$ & $30 \sim 67$ & $33 \sim 61$ & $33 \sim 57$ \\
\hline \multicolumn{5}{|l|}{ Menopause status } \\
\hline Premenopause & $34(61.8 \%)$ & $15(51.7 \%)$ & $19(73.1 \%)$ & $13(81.3 \%)$ \\
\hline Postmenopause & $21(38.2 \%)$ & $14(48.3 \%)$ & $7(26.9 \%)$ & $3(18.7 \%)$ \\
\hline \multicolumn{5}{|l|}{ Tumor size } \\
\hline$\leq 2 \mathrm{~cm}$ & $7(12.7 \%)$ & $2(6.9 \%)$ & $5(19.2 \%)$ & $1(6.3 \%)$ \\
\hline $2 \sim 5 \mathrm{~cm}$ & $35(63.6 \%)$ & $21(72.4 \%)$ & $14(53.8 \%)$ & $8(50 \%)$ \\
\hline$>5 \mathrm{~cm}$ & $13(23.7 \%)$ & $6(20.7 \%)$ & $7(27 \%)$ & $7(43.7 \%)$ \\
\hline Stage II & $30(54.5 \%)$ & $15(51.7 \%)$ & $15(57.7 \%)$ & $8(50 \%)$ \\
\hline III & $25(45.5 \%)$ & $14(48.2 \%)$ & $11(42.3 \%)$ & $8(50 \%)$ \\
\hline \multicolumn{5}{|l|}{ Hormonal receptor } \\
\hline $\mathrm{ER}^{+}(+)$ & $29(52.7 \%)$ & $15(51.7 \%)$ & $14(53.8 \%)$ & $7(43.8 \%)$ \\
\hline $\mathrm{PR}^{\neq}(+)$ & $24(43.6 \%)$ & $8(27.6 \%)$ & $10(38.5 \%)$ & $7(43.8 \%)$ \\
\hline \multicolumn{5}{|l|}{ Nuclear grade } \\
\hline 2 & $27(49.1 \%)$ & $15(51.7 \%)$ & $12(46.2 \%)$ & $4(25 \%)$ \\
\hline 3 & $28(50.9 \%)$ & $14(48.2 \%)$ & $14(53.8 \%)$ & $10(62.5 \%)$ \\
\hline \multicolumn{5}{|l|}{ Histologic grade } \\
\hline 1,2 & $23(41.8 \%)$ & $13(44.8 \%)$ & $10(38.5 \%)$ & $4(25 \%)$ \\
\hline 3 & $32(58.2 \%)$ & $16(55.2 \%)$ & $16(61.5 \%)$ & $10(62.5 \%)$ \\
\hline \multicolumn{5}{|l|}{ Lymphatic invasion } \\
\hline$(+)$ & $31(56.4 \%)$ & $13(44.8 \%)$ & $18(69.2 \%)$ & $12(75.0 \%)$ \\
\hline$(-)$ & $24(43.6 \%)$ & $16(55.2 \%)$ & $8(30.8 \%)$ & $4(25.0 \%)$ \\
\hline \multicolumn{5}{|l|}{ Vascular invasion } \\
\hline$(+)$ & $19(34.5 \%)$ & $11(37.9 \%)$ & $8(30.8 \%)$ & $5(31.3 \%)$ \\
\hline$(-)$ & $36(65.5 \%)$ & $18(62.1 \%)$ & $18(69.2 \%)$ & $11(68.7 \%)$ \\
\hline \multicolumn{5}{|l|}{ P53 $(n=64)$} \\
\hline$(+)$ & $16(32.7 \%)$ & $9(34.6 \%)$ & $7(30.4 \%)$ & $9(60.0 \%)$ \\
\hline$(-)$ & $33(67.3 \%)$ & $17(65.4 \%)$ & $16(69.6 \%)$ & $6(40.0 \%)$ \\
\hline \multicolumn{5}{|l|}{ Radiotherapy } \\
\hline$(+)$ & $41(74.5 \%)$ & $22(75.9 \%)$ & $19(73.1 \%)$ & $6(37.5 \%)$ \\
\hline$(-)$ & $14(25.5 \%)$ & $7(24.1 \%)$ & $7(26.9 \%)$ & $10(62.5 \%)$ \\
\hline
\end{tabular}

${ }^{*}$ high-dose chemotherapy and stem cell transplantation, ${ }^{\dagger}$ estrogen receptor, ${ }^{\ddagger}$ progesterone receptor

fen for 5 years after chemotherapy, and relapsed patients received salvage therapy.

\section{2) Treatment results}

Two patients of group I showed disease relapse during CMF chemotherapy. In group II, relapse was discovered in 2 patients during chemotherapy, and a median 6 courses of chemotherapy were given (range $3 \sim 8$ ). With a median follow-up of 27.1 months for living patients, a total of 24 (33.8\%) patients developed new disease manifestations; 12 patients in group I, 8 patients in group II, and 4 patients in group III. The most frequent relapse occurred in distant sites; bone 7, lung 5, SCLN 5 , liver 2, and brain 2. Among those patients that received postoperative radiotherapy, the incidence of local relapse was $6.4 \%$ (3/47). Three patients did not receive radiotherapy because of early disease relapse during chemotherapy. Eleven patients died in recurrence; 5 patients in group I, and one patient in each of groups II and III.
Three-year DFS of all patients was $57.1 \%$ and the estimated 3-year OS was $86.1 \%$ (Table 3). No difference was found in the 3-year DFS rates of the conventional dose chemotherapy group (group I/II) and HDC group (group III) (55.4\% vs. $62.7 \%, P$-value 0.1733$)$, and nor in their 3 -year OS $(83.0 \%$ vs. $93.8 \%, P$-value 0.4109$)$. In addition, no difference was found in the 3 -year DFS $(59.0 \%$ vs. $49.4 \%, P$-value 0.9964$)$, or in the 3-year OS of groups I and II $(78.2 \%$ vs. $90.9 \%, P$-value $0.2898)$. Fig. 1 shows the 3 -year DFS of the three treatment groups. In patients treated with adriamycin followed by CMF (group I), no difference in 3-year DFS was observed between patients treated with 4 courses of adriamycin (4A-CMF) and those treated with 3A-CMF (62.5\% vs 42.9\%, $P$-value 0.3358$)$. However, patients treated with 4A-CMF showed better 3-year OS than those treated with 3A-CMF $(95.5 \%$ vs $42.9 \%, P$-value 0.0052) (Fig. 2). 
Table 3. Survival rate

\begin{tabular}{|c|c|c|c|c|c|}
\hline & \multicolumn{3}{|c|}{$\mathrm{HDC}^{*}(-)$} & \multirow{2}{*}{$\begin{array}{c}\mathrm{HDC}(+) \\
\quad(\mathrm{n}=16)\end{array}$} & \multirow{2}{*}{$\begin{array}{l}\text { Total } \\
(\mathrm{n}=71)\end{array}$} \\
\hline & $\begin{array}{l}\text { Total } \\
(\mathrm{n}=55)\end{array}$ & $\begin{array}{l}\text { A-CMF } \\
(n=29)\end{array}$ & $\begin{array}{c}\text { CAF } \\
(n=26)\end{array}$ & & \\
\hline \multicolumn{6}{|l|}{$\mathrm{OS}^{+}$} \\
\hline 1-Year OS & $100 \%$ & $100 \%$ & $100 \%$ & $100 \%$ & $100 \%$ \\
\hline 2-Year OS & $87.3 \%$ & $84.2 \%$ & $90.9 \%$ & $93.8 \%$ & $89.1 \%$ \\
\hline 3-Year OS & $83.0 \%$ & $78.2 \%$ & $90.9 \%$ & $93.8 \%$ & $86.1 \%$ \\
\hline \multicolumn{6}{|l|}{$\mathrm{DFS}^{\ddagger}$} \\
\hline 1-Year DFS & $87.3 \%$ & $93.1 \%$ & $80.8 \%$ & $93.8 \%$ & $88.7 \%$ \\
\hline 2-Year DFS & $68.8 \%$ & $66.4 \%$ & $74.0 \%$ & $87.1 \%$ & $73.4 \%$ \\
\hline 3-Year DFS & $55.8 \%$ & $59.0 \%$ & $49.4 \%$ & $62.7 \%$ & $57.1 \%$ \\
\hline
\end{tabular}

Table 4. Univariate analysis of prognostic factors

\begin{tabular}{|c|c|c|c|c|}
\hline Variables & $3-\mathrm{DFS}^{*}(\%)$ & $P$-value & $3-\operatorname{OS}^{\dagger}(\%)$ & $P$-value \\
\hline \multicolumn{5}{|l|}{ Age } \\
\hline$\leq 50$ & 56.8 & & 85.8 & \\
\hline$>50$ & 58.6 & 0.7142 & 87.0 & 0.765 \\
\hline \multicolumn{5}{|l|}{ Menopause status } \\
\hline Premenopause & 53.3 & & 86.0 & \\
\hline Postmenopause & 64.7 & 0.792 & 86.1 & 0.813 \\
\hline \multicolumn{5}{|l|}{ Tumor size } \\
\hline$\leq 2 \mathrm{~cm}$ & 31.3 & & 100 & \\
\hline $2 \sim 5 \mathrm{~cm}$ & 60.6 & & 85.6 & \\
\hline$>5 \mathrm{~cm}$ & 60.4 & 0.901 & 92.3 & 0.362 \\
\hline \multicolumn{5}{|l|}{ Stage } \\
\hline II & 53.3 & & 84.6 & \\
\hline III & 61.7 & 0.803 & 88.0 & 0.938 \\
\hline \multicolumn{5}{|c|}{ No. of involved LN } \\
\hline $10 \sim 20$ & 76.0 & & 91.3 & \\
\hline$>20$ & 44.1 & 0.041 & 79.8 & 0.444 \\
\hline \multicolumn{5}{|l|}{ ER receptor } \\
\hline$(-)$ & 54.6 & & 74.8 & \\
\hline$(+)$ & 66.7 & 0.039 & 96.9 & 0.042 \\
\hline \multicolumn{5}{|l|}{ PR receptor } \\
\hline$(-)$ & 47.8 & & 80.9 & \\
\hline$(+)$ & 73.2 & 0.028 & 95.7 & 0.227 \\
\hline \multicolumn{5}{|l|}{ Nuclear grade } \\
\hline 2 & 59.6 & & 88.9 & \\
\hline 3 & 58.2 & 0.932 & 82.8 & 0.469 \\
\hline \multicolumn{5}{|l|}{ Histologic grade } \\
\hline 1,2 & 65.6 & & 90.4 & \\
\hline 3 & 56.8 & 0.681 & 81.4 & 0.435 \\
\hline \multicolumn{5}{|l|}{ P-53 } \\
\hline$(-)$ & 61.6 & & 82.8 & \\
\hline$(+)$ & 62.0 & 0.441 & 90.3 & 0.499 \\
\hline \multicolumn{5}{|l|}{ HDC with SCT } \\
\hline$(-)$ & 55.8 & & 83.0 & \\
\hline$(+)$ & 62.7 & 0.259 & 93.8 & 0.916 \\
\hline
\end{tabular}

*3-year disease free survival, ${ }^{\dagger} 3$-year overall survival

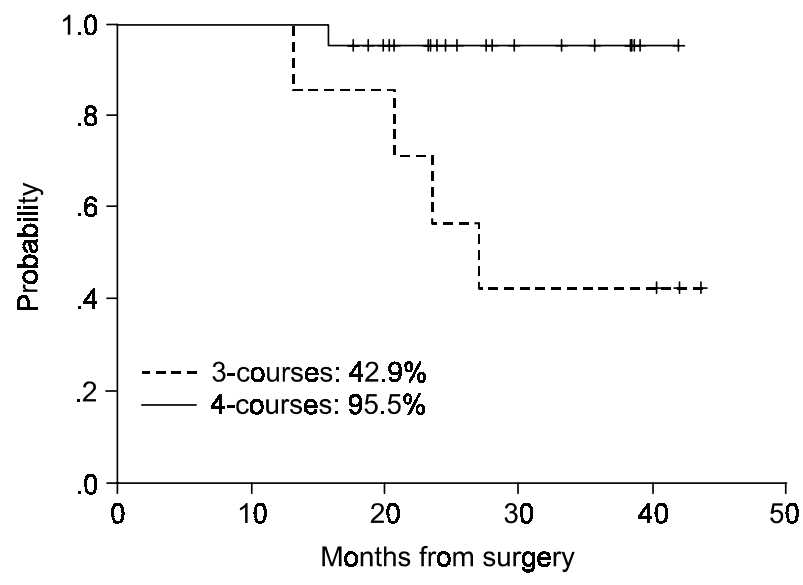

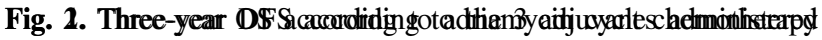
gropoptients treated with sequential adriamycin followed by CMF.

\section{3) Prognostic factors}

Three-year DFS and three-year OS related to the main patient and disease characteristics are detailed in Table 4. Twenty or more involved lymph nodes, and negative ER or PR receptor status were predictors of a shorter DFS. Age, menopausal state and tumor size were not significant predictors by univariate analysis. Although our data showed that adjuvant radiotherapy affected survival rate in patients treated with conventional chemotherapy (3-year DFS $71.3 \%$ vs. $15.3 \%$, 3-year OS $92.7 \%$ vs. $54.5 \%$ ), it could not be considered as a significant prognostic factor because some patients who suffered early relapse did not receive radiotherapy.

\section{4) Toxicity}

Thirteen of 29 patients in group I (44.8\%) and 8 of 26 patients in group II (30.8\%) experienced grade $3 / 4$ neutropenia, but only one patient in group II developed febrile neutropenia. The incidence of dose reduction or delay of chemotherapy was similar in groups I and II. This happened for 13/109 (11.9\%) courses of adriamycin and for 44/224 (19.6\%) courses of CMF in group I; and for 17/156 (10.9\%) courses of in group II. All patients of group III experienced febrile neutropenia during HDC, including 3 patients with microbiologically documented infection. However, this was successfully treatment by using appropriate antimicrobial agents. Liver function tests were available for 47 patients treated with conventional dose chemotherapy (group I/II), which was sufficient for liver toxicity analysis. Sixteen $(34 \%)$ of these 47 patients developed abnormal liver function, mainly elevated transaminase; 10 of the 16 patients were grade I and 6 grade II by the WHO toxicity criteria; $11 / 29(37.9 \%)$ in group I and 5/18 (27.8\%) in group II. Clinically, no detectable cardiac toxicity was noted during the follow-up period, and no chemotherapy-associated death occurred.

\section{DISCUSSION}


Previously, we reported upon the results of adjuvant chemotherapy on our breast cancer patients, and found that the 3-year and 5-year DFS of patients with 10 or more positive nodes were $46 \%$ and $29 \%$, respectively, and that the 5-year OS was $54 \%$ (13). In 1997, we decided to treat such patients with HDC and SCT, if patients agreed, and otherwise, to treat with either a sequential regimen of adriamycin followed by CMF or conventional CAF. This study shows that the 3-year DFS of the HDC and SCT group was same as that of the adriamycin containing chemotherapy group $(57.1 \%$ vs. $55.8 \%)$.

Over the past decade, a great deal of effort, such as that upon HDC with SCT, has gone into improving treatment results in high-risk breast cancer patients with 10 or more involved axillary nodes $(14 \sim 16)$. Some earlier reports found that HDC followed by SCT gave better DFS. Peter et al. (14) reported a $71 \%$ DFS and a $78 \%$ OS at 5 years in 85 patients who received 4 cycles of CAF adjuvant chemotherapy followed by HDC with SCT, and Gianni et al. (15) reported a 57\% DFS and a $70 \%$ OS at 5 years in 67 patients. However, these improved results were criticized and were later attributed to extensive screening for metastatic disease. Indeed, Crump et al. (17) reported that $23 \%$ of patients were excluded from HDC and SCT because of the presence of metastatic disease after an extensive work-up. These patients normally might have been considered as not having metastasis and could have received SCT. Furthermore, the on-site review of the positive study of Bezwoda could not confirm the validity of their study (18). In view of these facts, our study result is not unexpected.

Attempts have also been made to improve the results of adjuvant chemotherapy in these patients by using adriamycin. Misset et al. (19) reported upon a 16 year median follow-up of a prospective randomized adjuvant study that compared classical CMF vs. ACFV (CAF plus vincristine). Their results confirmed the added value of anthracycline-based combination chemotherapy. The difference in the observed outcomes in favor of ACFV was significant in premenopausal patients and in postmenopausal patients with 10 nodes or more. Buzdar et al. (7) reported their results of an adjuvant CAF based chemotherapeutic regimen in 283 patients with 10 or more positive nodes. The dosage of adriamycin used was not uniform, but a 7 year DFS of $65 \%$ was obtained in patients who received $60 \sim 75 \mathrm{mg} / \mathrm{m}^{2}$ of adriamycin. However, they reported that this was not statistically different from the 7-year DFS of $36 \%$ to $52 \%$ observed in patients who received a lower dose of adriamycin. The Milan group used a somewhat different approach by adding adriamycin. When adriamycin was used after CMF ( 8 courses of CMF followed by 4 courses adriamycin), the result was no different that obtained using 12 courses of CMF in patients with $1 \sim 3$ positive nodes (20). However, when 4 cycles of adriamycin was used before 8 cycles of CMF, the results obtained were better than in a program that alternated adriamycin and CMF $(9,21)$. Specifically, median DFS in patients with more than 10 positive nodes were 57 and 38 months respectively in the two groups, and favored adriamycin-followed by CMF. The 5-year DFS of patients with 10 or more nodes was $50 \%$ in the group treated with adriamycin followed by CMF, compared to $24 \%$ for those treated with the alternating regimen. It is believed by the authors that early intensive adriamycin treatment (a total adri- amycin dose $300 \mathrm{mg} / \mathrm{m}^{2}$ spread over the first 9 weeks in contrast to over 27 weeks) could have caused the difference. Though the above Milan results seem to be very impressive, it is not certain that they are really better than CAF since no randomized study has compared this regimen to CAF. Our study is not a prospective randomized comparative study and the follow-up period was short, but the regimen used, namely, 4A-CMF is exactly the same as the Milan regimen. Furthermore, both the 4A-CMF and the CAF treatment were given to patients with the same characteristics, in the same institution over the same period of time, which adds credibility to comparisons made between CAF and those of the Milan regimen. The DFS at 3 years were $62.5 \%$ (4A-CMF) and $49.4 \%$ (CAF) in our study, which was not statistically different. The 3-year DFS and the 5-year DFS of the Milan study of patients with 10 or more nodes was around $56 \%$ (as plotted on their curve) and $50 \%$ respectively, which is comparable with our 3-year DFS results upon the 4A-CMF and CAF groups. However, the Milan patients survival curve of the two arms began to separate each other in favor of adriamycin followed by CMF (4A-CMF) after 3 years had passed. Moreover, the relatively small size of our study would probably have prevented our being able to observe any separation of the curves.

The 4A-CMF regimen, though effective, requires a much longer duration of treatment. A modified, relatively shorter course of the same regimen was examined by Hsieh et al. (22). This consisted of 3 courses of adriamycin followed by 6 courses of CMF. Otherwise, the dosage and interval used were the same as those used in the Milan study. They reported a 47.8\% 3-year DFS in patients with 10 or more nodes. Although this $47.8 \%$ 3-year DFS cannot be directly compared to our result of $62.5 \%$ or to the $56 \%$ Milan result, five of the seven patients in our present study who received only three courses of adriamycin followed by CMF (3A-CMF) had recurrences during the study period. The 3-year OS of these patients was $42.9 \%$ versus the $95.5 \%$ of the $4 \mathrm{~A}-\mathrm{CMF}$ patients ( $P$-value 0.0052 ). However, the 3 -year DFS was not statistically different (42.9\% vs. $62.5 \%$ ). Though it is difficult to definitively interpret this finding given the scale of the study, the total dose of $225 \mathrm{mg} / \mathrm{m}^{2}$ in 3 cycles repeated every 3 weeks seems to have produced a poorer result than the $300 \mathrm{mg} / \mathrm{m}^{2}$ in 4 cycles every 3 weeks. Adriamycin at $240 \mathrm{mg} / \mathrm{m}^{2}$ in total is widely accepted as a standard treatment in the USA and has been reported to be effective (23). In addition, it has been reported that there seems to be a threshold for effective adriamycin dosage according to a study that compared $60 \mathrm{mg} / \mathrm{m}^{2}, 75 \mathrm{mg} / \mathrm{m}^{2}$, and $90 \mathrm{mg} / \mathrm{m}^{2}$ (24). While our result supports the suggestions of the Milan investigators, namely that early intensive adriamycin is an important factor that affects the outcome of adjuvant treatment, it raises the question whether $225 \mathrm{mg} / \mathrm{m}^{2}$ of adriamycin during the early period of an adjuvant treatment is inferior to $240 \mathrm{mg} / \mathrm{m}^{2}$ or to a higher dose.

Both of the chemotherapy regimens were reasonably well tolerated, and required either a dose reduction or a delay in the treatment in only around $10 \%$ of the cycles (adriamycin) and there was no treatment related mortality. Interestingly, the elevation of liver enzymes to WHO grade 2 was seen in 16 (34\%) of the 47 patients of groups I and II in whom liver toxicity was evaluable. Though we could not find any study 
reporting hepatotoxicity from usual adjuvant chemotherapy outside of HDC and SCT in breast cancer patients, these abnormalities of liver function were somewhat expected in our patients since the majority of Korean patients take a large variety of other non-traditional, "alternative medicines" few of which have been scientifically studied to determine their efficacies or toxicities.

\section{CONCLUSIONS}

Adriamycin-based combination chemotherapy was as effective as HDC with SCT in patients with 10 or more positive lymph nodes as assessed by 3-year DFS. No difference was seen in the 3-year DFS's of the CAF group and the 4A-CMF group. Three courses of adriamycin seemed to be inadequate compared to 4 courses of adriamycin as a sequential program of adriamycin followed by CMF.

\section{REFERENCES}

1. Walker MJ, Osborne MD, Young DC, Schneebaum S, LaValle GJ, Farrar WB. The natural history of breast cancer with more than 10 positive nodes. Am J Surg 1995;169:575-579.

2. Nemoto T, Vana J, Bedwani RN, Baker HW, McGregor FH, Murphy GP. Management and survival of female breast cancer: Results of a national survey by the American College of Surgeons. Cancer 1980;45:2917-2924.

3. Bonadonna G, Valagussa P. Adjuvant systemic therapy for resectable breast cancer. J Clin Oncol 1985;3:259-275.

4. Bonadonna G, Valagussa P, Moliterni A, Zambetti M, Brambilla C. Adjuvant cyclophosphamide, methotrexate and fluorouracil in node-positive breast cancer: The results of 20 years of follow-up. N Engl J Med 1995;332:901-906.

5. Brambilla C, De Lena M, Rossi A, Valagussa P, Bonadonna G. Response and survival in advanced breast cancer after two noncross-resistant combinations. Br Med J 1976;1:801-804.

6. Fisher B, Redmond C, Wickerham DL, Bowman D, Schipper H, Wolmark N, Sass R, Fisher ER, Jochimsen P, LegaultPoisson S. Doxorubicin-containing regimens for the treatment of stage II breast cancer: the National Surgical Adjuvant Breast and Bowel Project experience. J Clin Oncol 1989;7:572-582.

7. Buzdar AU, Kau SW, Hortobagyi GN, Ames FC, Holmes FA, Fraschini G, Hug V, Theriault RL, McNeese MD, Singletary SE. Clinical course of patients with breast cancer with ten or more positive nodes who were treated with doxorubicincontaining adjuvant therapy. Cancer 1992;69:448-452.

8. Early Breast Cancer Trialists' Collaborative Group. Polychemotherapy for early breast cancer: an overview of the randomized trials. Lancet 1998;352:930-942.

9. Bonadonna G, Zambetti M, Valagussa P. Sequentail or alternating doxorubicin and CMF regimens in breast cancer with more than three positive nodes. Ten-year results. JAMA 1995; 273:542-547.

10. Rodenhuis S, Richel DJ. Randomized trial of high-dose chemotherapy and hematopoietic progenitor cell support in operable breast cancer with extensivie axillary lymph node involvement. Lancet 1998;352:515-521.

11. Peters WP, Rosner G, Vredenburgh J, Shpall E, Crump M, Richardson P, Marks L, Cirrincione C, Wood W, Henderson I, Hurd D, Norton L. A prospective randomized comparison of two doses of combination alkylating agents as consolidation after CAF in high-risk primary breast caner involving then or more axillary lymph nodes: preminary results of CALGB9082/ SWOG9114/NCIC MA-13. Proc Am Soc Clin Oncol 1999;18: 2A.

12. The Scandinavian Breast Cancer Study Group 9401. Results from a randomized adjuvant breast cancer study with high dose chemotherapy with CTCB supported by autologous bone marrow stem cell versus dose escalated and tailed FEC therapy. Proc Am Soc Clin Oncol 1999;18:3A.

13. Kim JG, Kim TW, Lee KJ, Kim SB, Suh C, Lee KH, Lee JS, Ahn SH, Chang H, Kim SH, Kim WK. Effect of adjuvant chemotherapy of operable breast cancer: survival and prognostic factor analysis. J Korean Cancer Assoc 1999;31:10181026.

14. Peters WP, Berry D, Vredenburgh JJ, Hussein A, Rubin P, Elkordy M, Ross M, Henderson IC, Budman D, Norton L, Weiss R, Hurd D. Five year follow-up of high-dose combination alkylating agents with ABMT as consolidation after standard-dose CAF for primary breast cancer involving $\geq 10$ axillary lymph nodes (Duke/CALGB 8782). Proc Am Soc Clin Oncol 1995; 14:933A.

15. Gianni AM, Siena S, Bregni M, Nicola MD, Orefice S, Cusumano F, Salvadori B, Luini A, Greco M, Zucali R, Rilke F, Zambetti M, Valagussa P, Bonadonna G. Efficacy, toxicity and applicability of high-dose sequential chemotherapy as adjuvant treatment in operable breast cancer with 10 or more involved axillary nodes: Five-year results. J Clin Oncol 1997; 15:2312-2321.

16. Peters WP, Ross M, Vredenburgh JJ, Meisenberg B, Marks LB, Winer E, Robert JK, Jones R, Shpall E, Wu K, Rosner G. High-dose chemotherapy and autologous bone marrow support as consolidation after standard-dose adjuvant therapy for high-risk primary breast cancer. J Clin Oncol 1993;11: 1132-1143.

17. Crump M, Goss PE, Prince M, Girouard C. Outcome of extensive evaluation before adjuvant therapy in women with breast cancer and 10 or more positive axillary lymph nodes. J Clin Oncol 1996;14:66-69.

18. Weiss RB, Rifkin RM, Stewart FM, Theriault RL, Williams LA, Beveridge RA. High-dose chemotherapy for high-risk primary breast cancer: an on-site review of the Bezwoda study. Lancet 2000;355:999-1003.

19. Misset JL, Palma M, Delgado M, Plagne R, Chollet P, Fumoleau P, Mevel BL, Belpomme D, Guerrin J, Fargeot P, Metz R, Ithzaki M, Hill C, Mathe G. Adjuvant treatment of node-positive breast cancer with cyclophosphamide, doxorubicin, fluorouracil, and vincristine versus cyclophosphamide, methotrexate, and fluorouracil: final report after a 16-year median follow-up duration. J Clin Oncol 1996;14:1136-1145.

20. Moliterni A, Bonadonna G, Valagussa P, Ferrari L, Zambetti M. Cyclophosphamide, methotrexate, and fluorouracil with and without doxorubicin in the adjuvant treatment of resectable breast cancer with one to three positive axillary nodes. J Clin Oncol 1991;9:1124-1130.

21. Buzzoni R, Bonadonna G, Valagussa P. Zambetti M. Adjuvant chemotherapy with doxorubicin plus cyclophosphamide, methotrexate, and fluorouracil in the treatment of resectable breast cancer with more than three positive axillary nodes. J Clin Oncol 1991;9:2134-2140.

22. Hsieh CI, Liu MC, Cheng SKH, Liu TW, Chen CM, Chen CC, Tsou MH, Juang AT. Adjuvant sequential chemotherapy with doxorubicin plus cyclophosphamide, methotrexate and 
fluorouracil (ACMF) with concurrent radiotherapy in resectable advanced breast cancer. Am J Clin Oncol 2000;23:122127.

23. Wood WC, Budman DR, Korzun AH, Cooper MR, Younger J, Hart RD, Moore A, Ellerton JA, Norton L, Ferree CR. Dose and dose intensity of adjuvant chemotherapy for stage II, node-positive breast carcinoma. N Engl J Med 1994;330: 1253-1259.

24. Henderson IC, Berry D, Demetri G, Cirrincione C, Goldstein L, Martino S, Ingle JN, Cooper MR, Canellos G, Borden E, Fleming G, Holland JF, Graziano S, Carpenter J, Muss H, Norton L. Improved disease-free and overall survival from the addition of sequential paclitaxel $(\mathrm{T})$ but not from the escalation of doxorubicin (A) dose level in the adjuvant chemotherapy of patients with node-positive primary breast cancer. Proc Am Soc Clin Oncol 1998;17:390A. 